\title{
Asemptomatik inflamatuvar prostatit C-reaktif protein ve steril piyüri temelinde tahmin edilebilir mi?
}

\author{
Can asymptomatic inflammatory prostatitis be predicted based on \\ C-reactive protein and sterile pyuria?
}

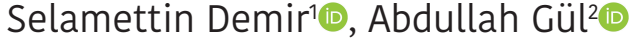

\section{öz}

AMAÇ: İnflamasyon, yüksek serum prostat spesifik antijen (PSA) seviyeleri ile başvuran hastaların biyopsi numuneleri incelendiğinde en sık görülen histolojik bulgulardan biri olmasına rağmen PSA seviyeleri üzerindeki etkisi hakkında çok az şey bilinmektedir. Bu çalışma, histolojik olarak saptanan asemptomatik prostatit olgularında c-reaktif protein (CRP) ve steril piyürinin klinik öneminin olup olmadığını araştırmak için yapılmıştır.

GEREÇ ve YÖNTEM: Bu makalede veriler kesitsel prospektif klinik çalışma ile elde edildi. Klinik prostatit bulguları olmayan ardışı 111 hasta normal rektal muayene bulguları, 3 ile $20 \mathrm{ng} / \mathrm{mL}$ arasında değişen PSA seviyeleri ve steril idrar kültürü sonuçlarına sahip idi. Tüm hastalara transrektal ultrasonografi eșliğinde 12 kadran prostat biyopsisi yapıldı. Operasyon öncesi üriner lökosit sayısı mikroskobik bir büyütme alanında (h.p.f) üç veya daha az olan hastalar non-piyüri grubu, üriner lökosit sayısı 3 'ten fazla olan hastalar piyüri grubu olarak sınıflandırıldı. Ayrıca CRP seviyeleri biyopsi öncesi hastaları gruplandırmak için kullanıldı. Alt gruplar birkaç klinik değişkene göre karşılaşıırıldı.

BULGULAR: Histolojik incelemede piyüri grubu hastalarını \%69'unda, non-piyüri grubu hastaların \%38,9'unda inflamasyon saptandı. Histolojik olarak saptanan inflamasyon oranları gruplar arasında anlamlı olarak farklıdı $(\mathrm{p}=0,008)$. Piyüri grubu, non-piyüri grubuna kıyasla anlamlı ölçüde daha yüksek total PSA seviyeleri ve serum CRP seviyeleri sergiledi ( $\mathrm{p}=0,041, \mathrm{p}=0,001$, sirasiyla). CRP negatif ve pozitif gruplar klinik değişkenler ve histolojik olarak saptanan inflamasyon oranları açısından benzerdi.

SONUC̣: Prostatik inflamasyonun CRP'den daha ziyade üriner lökosit sayısı ile daha güvenilir bir șekilde saptanabileceği gösterildi. Piyürili hastalar yüksek serum PSA seviyeleri sergiledi. Klinik prostatit bulguları olmayan hastalarda PSA yüksekliğinin nedeni olarak steril piyüri akılda tutulmalıdır. Üriner lökosit sayısı basitliği, kolaylığı ve invaziv olmamasından dolayı rutin ürolojik değerlendirmeye dahil edilmelidir.

Anahtar Kelimeler: Asemptomatik inflamatuvar prostatit, biyopsi, C-reaktif protein, piyüri, inflamasyon

\section{ABSTRACT}

OBJECTIVE: Inflammation is one of the most common histological evidence when prostate biopsy specimens of patients presenting with high PSA (Prostatespecific antigen) levels are examined, but little is known about its effect on PSA levels. This study was conducted to evaluate whether $\mathrm{C}$-reactive protein (CRP) and sterile pyuria has clinical significance in histologically-detected asymptomatic prostatitis cases.

MATERIAL and METHODS: In this article, the data were obtained by a crosssectional and prospective clinical study. One hundred eleven consecutive patients without clinical prostatitis had normal digital rectal examination findings, PSA levels ranging from 3 to $20 \mathrm{ng} / \mathrm{mL}$, and sterile urine culture results. All of them underwent transrectal ultrasound-guided 12-core prostatic biopsy. Preoperatively, patients who had urinary leukocyte count 3 or less than $3 /$ high power field (h.p.f) were classified as non-pyuria, while those with urinary leukocyte count more than $3 /$ high power field (h.p.f) were classified as pyuria. The serum CRP level was also used to categorize patients before the biopsy. The subgroups were compared regarding a number of clinical variables.

RESULTS: Histological examination revealed inflammation in $69 \%$ of pyuria patients and $38.9 \%$ of non-pyuria patients. Histologically-detected inflammation rate was significantly different in the groups $(\mathrm{p}=0.008)$. The pyuria group exhibited significantly higher total PSA levels compared to the non-pyuria group ( $\mathrm{p}=0.041)$, as well as significantly higher serum CRP levels $(\mathrm{p}=0.001)$. CRP positive and negative groups were similar regarding clinical variables and histologically-detected inflammation rates.

CONCLUSION: It has been shown that prostatic inflammation can be detected more reliably with urinary leukocyte count rather than serum CRP. Patients with pyuria exhibited high levels of serum PSA. Sterile pyuria should be kept in mind as a cause of elevated PSA in patients without clinical prostatitis findings. Urinary leukocyte count should be incorporated in routine urological evaluation thanks to its simplicity, convenience, and non-invasiveness.

Keywords: Asymptomatic inflammatory prostatitis, biopsy, C-reactive protein, pyuria, inflammation

\section{GíRiș}

${ }^{2}$ Sağlık Bakanlığı Sağlık Bilimleri Üniversitesi, Van Eğitim ve Araştırma Hastanesi, Üroloji Bölümü, Van, Türkiye

\section{Yazışma Adresi/ Correspondence:}

Uzm. Dr. Selamettin Demir

İkinisan Kavşağı, İpekyolu Cad. Özel Akdamar Hastanesi, Üroloji kliniği, Van, Türkiye Tel. $\quad$ +905057987925

E-mail: drselami1978@hotmail.com

Geliş/ Received: $\quad 04.10 .2018$

Kabul/ Accepted: 23.10 .2018
Serum total prostat spesifik antijen (PSA) keşfedildiğinden beri prostat kanserinin (PCa) taramasında yaygın olarak kullanılan çok önemli bir belirteç olmaya devam etmektedir. ${ }^{[1,2]}$ PSA seviyesi, PCa'ya spesifik olmayıp ek olarak benign prostat hiperplazisi (BPH) ve akut veya kronik prostatit gibi benign durumlar ile üretral enstrümantasyon ve 
rektal muayene gibi manipülasyonlarda da artabilmektedir. $^{[1-3]}$ PSA'nın sensitivitesinin de sınırlı olmasından dolayı serbest PSA yüzdesi, PSA dansitesi (PSAD) ve PSA velositesi gibi çeşitli PSA ilişkili parametreler PSA'nın prediktif değerini arttırmak için kullanılmaktadır. ${ }^{[1,2]}$

Prostat biyopsi spesmenlerinde prostatik inflamasyonun histolojik bulguları, BPH'lı ve PCa’lı hastalar yanında asemptomatik hastalarda da sık görülmektedir. ${ }^{[3]}$ Yüksek serum PSA nedeni ile prostat biyopsisi yapılan asemptomatik hastalarda histolojik inflamasyon ile serum PSA seviyesi arasındaki ilişkiyi araştıran çalışmalarda sonuçlar tartışmalı görülmektedir. ${ }^{[4-10]} \mathrm{Bu}$ asemptomatik hastalarda yüksek oranda histolojik inflamasyonun olduğu saptanmasına rağmen serum PSA seviyesi üzerinde ne derece etkisi olduğu hakkında az şey bilinmektedir. ${ }^{[11-14]}$

Bu güncel çalışmanın amacı, transrektal ultrasonografi eşliğinde 12 kadran prostat biyopsisi öncesi üriner lökosit sayısı ve serum CRP seviyesinin yaş, total PSA, serbest PSA/ total PSA oranı, PSAD değeri ve prostat hacmi gibi klinik değişkenler ile korelasyonunu göstermek ve ayrıca histolojik inflamasyon ve PCa saptama oranları üzerinde prediktif değerini araştırmaktır.

\section{GEREÇ VE YÖNTEM}

Tüm hastalardan işlem öncesi bilgilendirilmiş onam ve SBÜ Van Eğitim ve Araştırma Hastanesi etik kuruldan etik onay alındı. Bu kesitsel prospektif klinik çalışmaya, kliniğimize Ocak 2018 ve Eylül 2018 tarihleri arasında klinik prostatit bulguları olmayan ve PSA yüksekliği nedeniyle başvuran ardışı toplam 111 hasta dahil edildi. Hastaların ortak klinik özellikleri; 3 ila $20 \mathrm{ng} / \mathrm{mL}$ arası serum PSA seviyesi, normal rektal muayene bulguları ve steril idrar kültürü sonuçlarına sahip olmaları idi. Serum PSA seviyesini yükseltebilen klinik prostatit bulguları, makroskopik piyürisi ve idrar kültüründe üremesi olan, ayrıca serum CRP seviyesini potansiyel olarak etkileyebilen sistemik inflamatuvar hastalıklara sahip olan hastalar çalışmadan dışlandı. Kan ve idrar numuneleri biyopsi ve rektal muayeneden 2-5 gün önce elde edildi. Bütün hastalara operasyon sabahı lavman ve biyopsiden bir gün önce başlanmak üzere yedi gün boyunca günde iki defa $500 \mathrm{mg}$ siprofloksasin verildi. Tedavi öncesi bir mikroskobik büyütme alanında (h.p.f) üç veya daha az üriner lökosit sayısına sahip olan hastalar non-piyüri, üçten fazla üriner lökosit sayısına sahip olanlar ise piyüri grubu olarak sınıflandırıldı. Ayrica serum CRP seviyesi $0,3 \mathrm{mg} / \mathrm{dL}$ veya daha fazla olan hastalar CRP pozitif, CRP seviyesi $0,3 \mathrm{mg} / \mathrm{dL}$ 'den düşük olanlar ise CRP negatif grup olarak sınıflandırıldı. CRP'nin cut-off değeri $\% 93$ spesifiklik ile $0,3 \mathrm{mg} / \mathrm{dL}$ olarak alındı. ${ }^{[15]}$ Tedavi öncesi serbest ve total PSA değerleri Elecsys PSA kit (Roche Cobas 411, Tokyo, Japan) ve CRP değerleri latex CRP immunodetection kit (CRP-Latex 'CRPLX', Roche, Germany and Model no. 6000; Hitachi, Tokyo, Japan) kullanılarak ölçüldü. İdrar örneği otomatik santrifüj analiz cihazı ve sşık mikroskobu (Roche Miditron Junior II, Germany) ile analiz edildi. Prostatın transrektal ultrasonografisi 6,5 $\mathrm{MHz}$ endorektal prob kullanılarak yapıldı. Hastalar sedo-analjezi altında cenin pozisyonunda uzanırken prostat hem sagittal hem de transvers planda tarand. Prostat hacmi elipsoid formül (genişlik $\times$ uzunluk $\times$ yükseklik $\times 0,523$ ) kullanılarak hesaplanırken PSAD değeri ise total PSA'nın prostat hacmine bölünmesi ile hesaplandı. Her hastaya transrektal ultrasonografi rehberliğinde 12 kadran prostat biyopsisi otomatik biyopsi aparatına uygun 18 gauge iğne kullanılarak yapıldı. Biyopsi numuneleri patoloji laboratuarında usulüne uygun boyandı ve histolojik olarak incelendi. Prostatın kronik inflamasyon tanısı biyopsi spesmenlerinde lenfosit, plazma hücreleri ve/veya histiosit gibi kronik inflamasyon hücrelerinin bulunması ile patologlar tarafindan kondu. ${ }^{[16]}$

\section{İstatistiksel analiz}

Veriler, SPSS (IBM SPSS for Windows, ver. 24) programında, bağımsız t testi ve Mann Whitney U testi kullanılarak ortalama \pm standart sapma (means $\pm S D$ ) şeklinde verildi. İstatistiksel anlamlılık $\mathrm{p}<0,05$ şeklinde gösterildi.

\section{BULGULAR}

Çalışmaya dahil edilen hastaların özelliği Tablo 1'de gösterilmiştir. Histolojik olarak hastaların \%81,1'i $(\mathrm{n}=90)$ $\mathrm{BPH}$ ve \%18,9'u (n=21) PCa olarak saptandı. Klinik değişkenler bakımından PCa ve BPH hastalarının karşılaştırılması Tablo 1'de verilmiştir. Ayrıca histolojik incelemede biyopsi numunelerinin \%49,5'inde $(\mathrm{n}=55)$ inflamasyon gösterildi. PCa ve BPH'lı hastaların ortalama yaşları sırasıyla $66,57 \pm 7,69$ ve $64,8 \pm 7,97$ idi $(\mathrm{p}=0,197)$. PCa'lı hastalar BPH'lı hastalara nazaran anlamlı derecede daha yüksek total PSA seviyelerine sahipti $(\mathrm{p}=0,002)$. Fakat serbest/total PSA oranları açısından iki grup arasında anlamlı fark yoktu. Ayrıca ortalama prostat hacmi, PCa'lı hastalara nazaran BPH'lı hastalarda anlamlı olarak daha büyük $(\mathrm{p}=0,047)$ iken PSAD değeri ise $B P H^{\prime} l_{1}$ hastalara nazaran PCa'lı hastalarda anlamlı derecede daha yüksek saptand $1(p=0,001)$. Fakat histolojik inflamasyon oranı açısından iki grup arasında anlamlı bir fark saptan$\operatorname{mad} 1(p=0,244)$.

Bu çalışmada üriner lökosit sayısı dağılımına göre hastaların \%35,1'i (n=39) piyüri grupta iken kalan 72 hasta $(\% 64,9)$ non-piyüri grubunda idi. Tablo 2 , iki grup arasında histolojik inflamasyon oranları ile birlikte klinik 
değişkenlerin karşılaştırmasını vermektedir. İki grup arasında yaş, serbest/total PSA oranı, prostat hacmi ve PSAD değeri açısından anlamlı fark yoktu. Ancak total PSA seviyesi non-piyüri gruba kıyasla piyüri grubunda anlam$l_{1}$ ölçüde daha yüksek saptandı $(\mathrm{p}=0,041)$. PCa saptama oranları açısından iki grup arasında fark yok iken histolojik inflamasyon oranları piyüri grubunda anlamlı ölçüde daha yüksek bulundu (\%69'a karş1 \%38,1, p=0,008).
Operasyon öncesi CRP seviyelerine göre hastaların 79'u $(\% 71,1)$ CRP pozitif grupta, kalan $32(\% 28,9)$ hasta CRP negatif grupta idi. Tablo 3, iki grup arasında histolojik inflamasyon ve PCa saptama oranları ile birlikte klinik değişkenlerin karşılaştırmasını sunmaktadır. İki grup arasında yaş, total PSA, prostat hacmi ve PSAD değeri gibi değişkenlerin yanı sıra histolojik inflamasyon ve PCa saptama oranları açısından da anlamlı bir fark gözlenmedi.

Tablo 1. Çalışmaya dahil edilen hastaların özellikleri

\begin{tabular}{|c|c|c|c|}
\hline & $B P H(n=90)$ & $\operatorname{PCa}(n=21)$ & $p$ \\
\hline Yaş (yıl) & $64,08 \pm 7,97(41,0-78,0)$ & $66,57 \pm 7,69(47-79)$ & 0,197 \\
\hline Üriner lökosit sayısı & $10,51 \pm 20,26(1-85)$ & $11,71 \pm 24,58(1-90)$ & 0,832 \\
\hline $\mathrm{CRP}(\mathrm{mg} / \mathrm{dL})$ & $1,34 \pm 1,65(0,1-7,79)$ & $0,96 \pm 0,77(0,1-2,68)$ & 0,325 \\
\hline TPSA (ng/mL) & $6,75 \pm 2,68(2,8-13,78)$ & $9,61 \pm 4,69(3,70-19,80)$ & $0,002^{*}$ \\
\hline Prostat hacmi (mL) & $60,77 \pm 35,8(17-250)$ & $44,2 \pm 22,21(21-93)$ & $0,047^{*}$ \\
\hline Serbest/total PSA oranı (\%) & $20 \pm 8(6-37)$ & $23 \pm 24(4-60)$ & 0,546 \\
\hline PSAD & $0,13 \pm 0,06(0,03-0,31)$ & $0,26 \pm 0,20(0,08-0,82)$ & $0,001^{*}$ \\
\hline Histolojik inflamasyon oranı & $\% 52,2$ (47/90) & $\% 38,1(8 / 21)$ & 0,244 \\
\hline
\end{tabular}

Ortalama \pm Standart sapma; negatif, serum CRP $<0,3 \mathrm{mg} / \mathrm{dL}$; pozitif, serum CRP $\geq 0,3 \mathrm{mg} / \mathrm{dL}$; CRP, C-reaktif protein; TPSA, total prostat spesifik antijen; PSAD, PSA dansitesi; PCa, prostat kanseri.

Tablo 2. Piyüri ve non-piyüri gruplarda histolojik inflamasyon oranı, PCa saptama oranı ve klinik değişkenler

\begin{tabular}{lccc}
\hline & Non-piyüri grup $(n=72)$ & Piyüri grup $(n=39)$ & $p$ \\
\hline Yaş (yıl) & $63,67 \pm 8,62(41,0-78,0)$ & $67 \pm 7,12(53-79)$ & 0,060 \\
CRP $(\mathrm{mg} / \mathrm{dL})$ & $0,77 \pm 0,84(0,1-3,47)$ & $2,42 \pm 2,14(0,31-7,79)$ & $0,001^{*}$ \\
TPSA $(\mathrm{ng} / \mathrm{mL})$ & $6,63 \pm 2,62(2,98-15,07)$ & $8,06 \pm 4,09(2,80-19,80)$ & $0,041^{*}$ \\
Prostat hacmi (mL) & $55,4 \pm 37,6(17-250)$ & $59,6 \pm 29,7(24-120)$ & 0,587 \\
Serbest/total PSA oranı (\%) & $18 \pm 10(4-37)$ & $22 \pm 13(10-60)$ & 0,432 \\
PSAD & $0,15 \pm 0,08(0,03-0,47)$ & $0,16 \pm 0,13(0,04-0,71)$ & 0,586 \\
Histolojik inflamasyon oranı & $\% 38,9(28 / 72)$ & $\% 69(27 / 39)$ & $0,008 *$ \\
PCa saptama oranı & $\% 18(13 / 72)$ & $\% 20,5(8 / 39)$ & 0,515 \\
\hline
\end{tabular}

Ortalama \pm Standart sapma; Non-piyüri, Üriner lökosit sayısı $\leq 3 /$ bir büyütme alanında; piyüri, Üriner lökosit sayısı >3/bir büyütme alanında; CRP, C-reaktif protein; TPSA, total prostat spesifik antijen; PSAD, PSA dansitesi; PCa, prostat kanseri.

Tablo 3. CRP negatif ve CRP pozitif gruplarda histolojik inflamasyon oranı, PCa saptama oranı ve klinik değişkenler

\begin{tabular}{lccc}
\hline & CRP negatif $(n=32)$ & CRP pozitif $(n=79)$ & $p$ \\
\hline Yaş (yıl) & $65,10 \pm 8,44(40-75)$ & $63 \pm 7,61(41-75)$ & 0,238 \\
TPSA $(\mathrm{ng} / \mathrm{mL})$ & $6,92 \pm 2,40(3,50-13,65)$ & $7,27 \pm 3,58(2,70-19,50)$ & 0,648 \\
Prostat hacmi (mL) & $59,13 \pm 33,34(17-140)$ & $51,93 \pm 22,55(19-105)$ & 0,244 \\
Serbest/total PSA oranı (\%) & $20 \pm 8(4-37)$ & $17 \pm 9(4-34)$ & 0,752 \\
PSAD & $0,14 \pm 0,05(0,04-0,30)$ & $0,16 \pm 0,11(0,04-0,80)$ & 0,462 \\
Histolojik inflamasyon oranı & $\% 50(16 / 32)$ & $\% 49,3(39 / 79)$ & 0,748 \\
PCa saptama oranı & $\% 12,5(4 / 32)$ & $\% 21,5(17 / 79)$ & 0,237 \\
\hline
\end{tabular}

Ortalama \pm Standart sapma; negatif, serum CRP<0,3 mg/dL; pozitif, serum CRP $\geq 0,3 \mathrm{mg} / \mathrm{dL}$; CRP, C-reaktif protein; TPSA, total prostat spesifik antijen; PSAD, PSA dansitesi; PCa, prostat kanseri. 


\section{TARTIȘMA}

PSA ölçümünün yaygınlaşması ile birlikte transrektal ultrasonografi eşliğinde prostat biyopsisi PCảnın tanısında yaygınlığı dramatik şekilde artan en önemli metodlardan biri olmaya devam etmektedir. ${ }^{[17]}$ Prostat biyopsisinin ana endikasyonunu rektal muayene ile birlikte serum PSA seviyesinin yükselmesi oluşturmaktadır. Ancak PSA seviyesi sadece PCa’lı hastalarda artmamaktadır. Prostat manipülasyonlarının yanı sıra prostatit ve BPH gibi benign durumlar, yaş ve prostat volümü gibi değişkenler ile de serum PSA seviyesi artabilmektedir. ${ }^{[6,18]}$

Serum PSA seviyesini yükseltebilen durumların yaygınlığ1 düşünüldüğünde yüksek PSA nedeniyle birçok hastaya prostat biyopsisi yapılmakta ve onların önemli bir yüzdesinde prostat kanseri saptanamamaktadır. Ayrıca yayımlanmış raporlarda biyopsinin hastaların \%21,2'si ile \%23,8'inde kanseri saptamada başarısız olduğu ve tekrar biyopsinin gerekliliği vurgulanmaktadır. ${ }^{[19,20]}$ Bazı durumlarda daha önce saptanamamış bir kanser alanını bulmak için daha fazla örnek almak ve hastalara tekrar biyopsi önermek zorunda kalınabilmektedir. İnvazivliği yanında, ağrı, hematüri, hematospermi, rektal kanama, üriner enfeksiyon, bakteriyemi, üriner retansiyon ve hatta septisemi gibi ciddi komplikasyonları içinde barındıran transrektal prostat biyopsisinin gereksiz tekrarı serum PSA seviyesini yükseltebilen diğer benign durumların tanısı ile önlenebileceği bildirilmiştir. ${ }^{[21]}$

Serum PSA seviyesini arttıran prostattaki histolojik inflamatuvar infiltrasyonun önemine 1991 yllında Brawn ve ark. ${ }^{[4]}$ tarafından dikkat çekilmiştir. Farklı çalışmalarda da biyopsi, açık ve endoskopik prostatektomi spesmenlerinde yüksek oranda inflamasyon oranları saptanmasına rağmen prostatik inflamasyon ile serum PSA arasındaki ilişki net olarak ortaya konamamıştır. ${ }^{[22]}$

İrani ve ark. ${ }^{[5]}$ tarafından 1997 yılında yapılan çalışmada prostatta sadece inflamatuvar hücre varlığının serum PSA yüksekliği ile ilişkili olmadığı ancak inflamasyonun yoğunluğu ve glanduler epitel hasarının sıklığı ile istatistiksel olarak anlamlı derecede ilişkili olduğu saptanmış ve bu serum seviyesindeki artışa, prostat kanallarının doku bütünlüğü bozulduğundan dolayı asinüs ve duktal laminadan PSA kaçağının yol açtı̆̆ı vurgulanmıştır. Farklı çalışmalarda da epitel hasarı ve inflamatuvar infiltrasyon derecesi ile serum PSA seviyesi arasındaki ilişki doğrulanmışıtır. ${ }^{[6,8,23,24]}$

$\mathrm{Bu}$ güncel çalışmada asemptomatik histolojik prostatitin prediktörü olarak üriner lökosit sayısı ve CRP değerleri incelenmiştir. Piyürili hastalarda yüksek PSA değerleri ve yüksek histolojik inflamasyon oranları gösterilmiştir
( $\mathrm{p}=0,041, \mathrm{p}=0,008$, sırasıyla). Bizim çalışmanın sonuçları, bahsi geçen yayınları destekler biçimde asemptomatik prostatitte piyüri bir belirteç olarak düşünüldüğünde histolojik inflamasyon ile serum PSA seviyesi arasındaki ilişkiyi göstermiştir.

İnflamatuvar barsak hastalığı olan hastalarda mide, karaciğer ve kolon kanseri gibi enfeksiyon etiyolojili kanserler kronik inflamasyon ile ilişkilendirilmektedir. İnflamasyon süreci yüksek reaktif oksijen bileşiklerini, akut faz reaktanlarını ve sitokinleri açığa çıkararak ve ayrıca hücre döngüsünü artırarak kanseri tetikleyip ilerlemesine sebep olabilmektedir. ${ }^{[25]}$ PCa'da prostatik inflamasyonun katkısı halen net olarak bilinmemesine rağmen muhtemel mekanizmalar olarak reaktif oksijen radikallerinin üretimi, siklooksijenz-2'nin indüklenmesi ile birlikte kanser gelişim ve ilerlemesine yol açan CRP gibi akut faz reaktanları ve IL-6 gibi sitokinlerin salınımı suçlanmaktadır. ${ }^{[26]} \mathrm{Bu}$ bulgular ışığında kronik prostatik inflamasyonda PCa riskinin arttığı ve ayrıca CRP, serum lökosit hücrelerinin PCa mortalitesi ve riskini arttırdığını gösteren bazı çalışmalar rapor edilmiştir. ${ }^{[27-30]} \mathrm{Bu}$ bulgulara rağmen $\mathrm{PCa}$ gelişim ve ilerlemesini tetiklemede albümin, haptaglobulin, CRP, serum lökosit hücreleri gibi sistemik inflamatuvar belirteçlerin rolü ile ilgili bulguların ikna edici olmadığı ve ayrıca prostatik inflamasyonun PCa'da gerçek rolünü aydınlatabilmek için uzun dönem takip ve iyi tanımlanmış klinik, moleküler ve epidemiyolojik çalışmaların gerekliliği vurgulanmıştır. ${ }^{[23,25]}$ $\mathrm{Bu}$ güncel çalışmamızda ise serum CRP seviyesi ve üriner lökosit sayısının PCa’yı saptamada prediktif değerinin olmadığı gösterilmiştir.

Retrospektif bir çalışmada 228 hastanın verileri incelenmiş ve biyopsi öncesi üriner lökosit sayısı ve CRP seviyelerine göre hastalar gruplara ayrılmıştır. ${ }^{[11]} \mathrm{Bu}$ çalışmada piyüri grubun $\% 58,1$ 'inde ve non-piyüri grubun $\% 34,1$ 'inde histolojik inflamasyon saptanmıştır $(\mathrm{p}=0,0014)$. Piyüri grupta histolojik inflamasyon oranlarının önemli ölçüde yüksek olduğu gözlenmiştir. Biyopsi sonuçlarında $\mathrm{BPH}$ tanısı alanların \%53,5'ine, PCa tanısı alanların ise \%14, 1 'ine histolojik inflamasyonun eşlik ettiği gösterilmiştir. Ancak, çalışmadan elde edilen sonuçlara göre serum CRP seviyesinin histolojik inflamasyonu saptamada klinik olarak yararlı olmadığı belirtilmiştir. ${ }^{[11]}$ Bizim sonuçlarda da biyopsi numunesinde BPH'ya yüksek histolojik inflamasyon oranının eşlik ettiği gözlenmiş olup ayrıca piyüri grupta muhtemelen inflamasyonun katkısı ile serum PSA ve CRP seviyesi daha yüksek bulunmuştur $(\mathrm{p}=0,041, \mathrm{p}=0,001$, s1rasıyla). Öte yandan bizim çalışmamızda da CRP negatif ve CRP pozitif grup arasında histolojik inflamasyon oranları açısından bir fark bulunamamıştır. 


\section{SONUÇ}

Normal rektal muayene bulguları ve artmış PSA seviyesi ile başvuran hastalara yüksek asemptomatik prostatit oranları eşlik edebilmektedir. Serum CRP seviyesinden daha ziyade üriner lökosit sayısı prostatik inflamasyon varllğııı öngörebilmektedir. Bizim sonuçlar ile üriner lökosit sayısının prostatik inflamasyonu saptamada güvenilir bir metod olduğu ve CRP seviyesinin ise yüksek PSA ile ilişkili olmadığı gösterilmiştir. Yüksek serum PSA'ya sahip steril piyürisi olan hastalarda eğer rektal muayene benign vasıfta ise biyopsiden önce steril piyüri sebeplerinin araştırılmasını ve varsa ekartasyonu sonrasında tekrar PSA bakılmasını önermekteyiz.

Hakem Değerlendirmesi

Dış bağımsız

Çıkar Çatışması

Yazarlar çıkar ilişkisi olmadığını beyan etmişlerdir.

\section{Finansal Destek}

Herhangi bir mali destek alınmamıştır.

\section{Peer-review}

Externally peer-reviewed.

\section{Conflict of Interest}

No conflict of interest was declared by the authors.

\section{Financial Disclosure}

No financial disclosure was received.

\section{KAYNAKLAR}

1. Polascik TJ, Oesterling JE, Partin AW. Prostate specific antigen: a decade of discovery -What we have learned and where we are going. J Urol 1999;162:293-306. [CrossRef]

2. Constantinou J, Feneley MR. PSA testing: an evolving relationship with prostate cancer screening. Prostate Cancer Prostatic Dis 2006;9:6-13. [CrossRef]

3. Kawakami J, Siemens DR, Nickel JC. Prostatitis and prostate cancer: implications for prostate cancer screening. Urology 2004;64:1075-80. [CrossRef]

4. Brawn PN, Speights VO, Kuhl D, Riggs M, Spiekerman AM, McCord RG, et al. Prostate-specific antigen levels from completely sectioned, clinically benign, whole prostates. Cancer 1991;68:1592-9. [CrossRef]

5. Irani J, Levillain P, Goujon JM, Bon D, Doré B, Aubert J. Inflammation in benign prostatic hyperplasia: correlation with prostate specific antigen value. J Urol 1997;157:1301-3. [CrossRef]

6. Schatteman PH, Hoekx L, Wyndaele JJ, Jeuris W, Van Marck E. Inflammation in prostate biopsies of men without prostatic malignancy or clinical prostatitis: correlation with total serum PSA and PSA density. Eur Urol 2000;37:404-12. [CrossRef]

7. Yaman O, Göğüş C, Tulunay O, Tokatli Z, Ozden E. Increased prostate-specific antigen in subclinical prostatitis: the role of the aggressiveness and extension of inflammation. Urol Int 2003;71:160-4. [CrossRef]

8. Simardi LH, Tobias-MacHado M, Kappaz GT, Taschner Goldenstein P, Potts JM, Wroclawski ER. Influence of asymptomatic histologic prostatitis on serum prostate-specific antigen: a prospective study. Urology 2004;64:1098-101. [CrossRef]
9. Kwak C, Ku JH, Kim T, Park DW, Choi KY, Lee E, et al. Effect of subclinical prostatic inflammation on serum PSA levels in men with clinically undetectable prostate cancer. Urology 2003;62:8549. [CrossRef]

10. Nickel JC. Prostatitis. Can Urol Assoc J 2011;5:306-15. [CrossRef]

11. Dalton DL. Elevated serum prostate-specific antigen due to acute bacterial prostatitis. Urology 1989;33:465. [CrossRef]

12. Neal DE, Moon TD, Clejan S, Sarma D. Prostate specific antigen and prostatitis I. Effect of prostatitis on serum PSA in the human and nonhuman primate. Prostate 1992;20:105-11. [CrossRef]

13. Yli-Hemminki TH, Laurila M, Auvinen A, Määttänen L, Huhtala H, Tammela TL, Kujala PM. Histological inflammation and risk of subsequent prostate cancer among men with initially elevated serum prostate-specific antigen (PSA) concentration in the Finnish prostate cancer screening trial. BJU Int 2013;112:735-41. [CrossRef]

14. Buddingh KT, Maatje MGF, Putter H, Kropman RF, Pelger RCM. Do antibiotics decrease prostate-specific antigen levels and reduce the need for prostate biopsy in type IV prostatitis? A systematic literature review. Can Urol Assoc J 2018;12:E25-30. [CrossRef]

15. Kato T, Suzuki H, Komiya A, Imamoto T, Naya $Y$, Tobe $T$, Ichikawa T. Clinical significance of urinary white blood cell count and serum C-reactive protein level for detection of non-palpable prostate cancer. Int J Urol 2006;13:915-9. [CrossRef]

16. Krieger JN, Nyberg L Jr, Nickel JC. NIH consensus definition and classification of prostatitis. JAMA 1999;282:236-7. [CrossRef]

17. Oliyide AE, Tijani KH, Jeje EA, Anunnobi CC, Adeyomoye AA, Ojewola RW, et al. The role of transrectal ultrasound-guided fineneedle aspiration biopsy in the diagnosis of prostate cancer: Sextant versus extended protocol. Niger Postgrad Med J 2017;24:236-9. [CrossRef]

18. Hammerer PG, McNeal JE, Stamey TA. Correlation between serum prostate specific antigen levels and the volüme of the individual glandular zones of the human prostate. J Urol 1995;153:111-4. [CrossRef]

19. Fleshner NE, O'Sullivan M, Fair WR. Prevalence and predictors of a positive repeat transrectal ultrasound guided biopsy of the prostate. J Urol 1997;158:505-8. [CrossRef]

20. Park SJ, Miyake H, Hara I, Eto H. Predictors of prostate cancer on repeat transrectal ultrasound-guided systematic prostate biopsy. Int J Urol 2003;10:68-71. [CrossRef]

21. Tobias-Machado M, Corrêa TD, De Barros EL, Wroclawski ER. Antibiotic prophylaxis in prostate biopsy: a comparative randomized clinical assay between ciprofloxacin, norfloxacin and chloramphenicol. Int Braz J Urol 2003;29:313-9. [CrossRef]

22. Blumenfeld W, Tucci S, Narayan P. Incidental lymphocytic prostatitis. Selective involvement with nonmalignant glands. Am J Surg Pathol 1992;16:975-81. [CrossRef]

23. Kandirali E, Boran C, Serin E, Semercioz A, Metin A. Association of extent and aggressiveness of inflammation with serum PSA levels and PSA density in asymptomatic patients. Urology 2007;70:7437. [CrossRef]

24. Gui-Zhong L, Libo M, Guanglin H, Jianwei W. The correlation of extent and grade of inflammation with serum PSA levels in patients with IV prostatitis. Int Urol Nephrol 2011;43:295-301. [CrossRef]

25. Arthur R, Williams R, Garmo H, Holmberg L, Stattin P, Malmström H, et al. Serum inflammatory markers in relation to prostate cancer severity and death in the Swedish AMORIS study. Int J Cancer 2018;142:2254-62. [CrossRef]

26. Toriola AT, Laukkanen JA, Kurl S, Nyyssönen K, Ronkainen K, Kauhanen J. Prediagnostic circulating markers of inflammation and risk of prostate cancer. Int J Cancer 2013;133:2961-7. [CrossRef] 
27. Platz EA, De Marzo AM. Epidemiology of inflammation and prostate cancer. J Urol 2004;171:S36-40. [CrossRef]

28. Thurner E, Krenn-Pilko S, Langsenlehner U, Stojakovic T, Pichler M, Gerger A, et al. The elevated C-reactive protein level is associated with poor prognosis in prostate cancer patients treated with radiotherapy. Eur J Cancer 2015;51:610-9. [CrossRef]
29. Xu Q, Chen YJ, Liu ZQ, Chu L, Fang JM, Zhang X, Zhao HX. Prognostic role of C-reactive protein in prostate cancer: a systematic review and meta-analysis. Asian J Androl 2014;16:46771. [CrossRef]

30. Aldemir M, Ener K, Dehni D, Ağras K, Kayıgil Ö. Evaluation of the relationship between prostate cancer and serum inflammation markers. Int J Nephrol Urol 2010;2:244-50. 